\title{
"DO WE NOT BLEED?" SANITATION, MENSTRUAL MANAGEMENT, AND HOMELESSNESS IN THE TIME OF COVID
}

\author{
HAWI TEIZAZU, ${ }^{\mathrm{a}}$ MARNI SOMMER, ${ }^{\mathrm{a}}$ CAITLIN GRUER, ${ }^{\mathrm{a}}$ DAVID \\ GIFFEN, ${ }^{b}$ LINDSEY DAVIS, ${ }^{\mathrm{b}}{ }^{\text {RACHEL FRUMIN }}{ }^{ }$KIM HOPPER ${ }^{\mathrm{a}}$
}

\section{INTRODUCTION}

Although access to adequate sanitation is formally recognized as a basic human right, ${ }^{1}$ public toilets have long been flagged as absent necessities by groups marginalized by class, gender, race, and ability in the United States. Navigating public spaces without the guarantee of reliable restrooms is more than a passing inconvenience for anyone needing immediate relief. This includes workers outside of traditional offices, people with medical conditions, caretakers of young children, or anyone without access to restroom amenities provided to customers. This absence is also gendered in ways that constrain the freedom of those who menstruate to participate in the public sphere. Managing menstrual hygiene requires twenty-four-hour access to safe, clean facilities, equipped for washing blood off hands and clothing and mechanisms for discreet disposal of used menstrual products. Public provision of such amenities is woefully inadequate in New York City (NYC), and homeless women ${ }^{2}$ especially bear the brunt of that neglect.

Public health concerns about open defecation, coupled with feminist complaints that their absence restricted women's ability to be out in public, catalyzed state investment to construct public toilets in the late 1800s. ${ }^{3}$ By 1907, eight had been built in NYC near

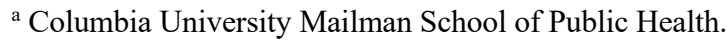

${ }^{\mathrm{b}}$ New York City Coalition for the Homeless.

${ }^{\mathrm{c}}$ Rachel Frumin is an employee of the City of New York. The views and opinions in this article are the personal work product of its authors and do not necessarily represent the views of opinions of the City of New York.

${ }^{1}$ Johanna Weststrate et al., The Sustainable Development Goal on Water and Sanitation: Learning from the Millennium Development Goals, 143 Soc. InDICATORs Rsch. 795, 800 (2018).

${ }^{2}$ We utilize the term "women" here but indicate in the paper that the needs of all people who menstruate should be considered.

${ }^{3}$ Taunya Lovell Banks, The Disappearing Public Toilet, 50 Seton Hall L. Rev. 1061-94 (2019).
} 
public markets, ${ }^{4}$ and by the 1930 s, the city built and renovated 145 comfort stations. ${ }^{5}$ However, changing public perceptions, vandalism, maintenance costs, and the City's fiscal crisis in the 1970s all combined to reduce their numbers and degrade their quality. Public pay toilets provided a brief respite before falling victim to protest by feminists, who were rightly dismayed by policies that required payments for public usage of toilets but not for urinals. ${ }^{6}$ Supply deteriorated, and by 2019 , NYC ranked ninety-third among large U.S. cities in per capita provision of public toilets. ${ }^{7}$ The remaining facilities are inadequately maintained and poorly monitored. ${ }^{8}$ The absence of public toilets poses an everyday challenge, but public health emergencies bring the need for public toilets into clear focus ${ }^{9}$ - as seen during the COVID-19 pandemic, which eliminated publicly accessible bathrooms in both private and public settings. That said, the effects of COVID on bathroom availability disproportionately affected those who were unable to heed the public health message to shelter at home - mobile "essential workers" and individuals experiencing homelessness.

Homelessness advocates have long complained that civic toilet scarcity amounts to de facto entrapment, turning biological necessities into "public nuisances" for want of

\footnotetext{
${ }^{4}$ Mike Wallace, Greater Gotham: A history of New York City from 1898 to 1919, at 551 (2017).

${ }^{5}$ Julie Chou, Kevin Gurley \& Boyeong Hong, The Need for Public Bathrooms 9 (2020).

${ }^{6}$ Robert J. Dunphy, Notes: The Campaign to Ban Pay Toilets (Published 1975), N.Y. Times (Sept. 14, 1975), https://www.nytimes.com/1975/09/14/archives/notes-the-campaign-to-ban-pay-toilets-notes-about-travelnotes.html [https://perma.cc/MZ3P-SXH8].

${ }^{7}$ Scott M. Stringer, OfF. of the N.Y.C. Comptroller, Discomfort Stations: The Conditions and AvAILABILITY OF NYC PARKS BATHROOMS (2019), https://comptroller.nyc.gov/wpcontent/uploads/documents/Discomfort_Stations_The_Conditions_and_Availability_of_NYC_Parks_Bathro oms.pdf [https://perma.cc/5WLE-GSA5].

${ }^{8}$ Chou, Gurley \& Hong, supra note 5, at 9-10.

${ }^{9}$ Health-related advocacy for public toilets primarily speaks to disease constituencies. In 2018, New York became one of seventeen states to ensure access for individuals with specific medical conditions. Crohn's and Colitis Fairness Act, N.Y. Gen. Bus. Law §§ 491-94 (McKinney 2018). Only Washington State recognizes universally shared biological urgencies, such as menstruation, and provides access to employee restrooms for all customers. Restroom Access, WASH. STATE DeP'T OF HeALth, https://www.doh.wa.gov/ForPublicHealthandHealthcareProviders/HealthcareProfessionsandFacilities/Restro omAccess\#2 [https://perma.cc/TP9T-7EGA].
} 
appropriate facilities. ${ }^{10}$ Criminalizing public urination and defecation in the absence of public facilities punishes the existence of individuals experiencing homelessness and challenges outreach workers' efforts to gain their trust. With women increasingly prominent among those living on the streets or in shelters, this scarcity also impedes managing menstruation. Default reliance on private business is no answer for anyone defying passable "customer" profiles. Nor does the recent success of NYC's "menstrual equity" efforts in schools, prisons, and shelters, with their primary focus on supplying menstrual products, suffice to cover the daytime needs of those on the move. ${ }^{11}$

\section{Public Restrooms: A Battleground for Equality and Inclusion}

Access to public restrooms is often framed in the language of rights. Federal law provides leverage prohibiting discrimination on the basis of race, religion, disability, etc., and has been drawn upon to improve the access such groups have to public restrooms. Such corrective measures also affirm the right to "participatory parity"12 in the public sphere by ensuring beneficiaries' access to enabling spaces and services. To date, access measures have not considered that facilities should be equipped to meet the needs of those who menstruate. Global efforts using a human rights framework may be useful in addressing this omission. ${ }^{13}$

\section{A. Legislation to Address Gendered Disparities}

Efforts at the federal level have yet to address gendered disparities in public toilet access, though state law and regulation have made some progress.

\footnotetext{
${ }^{10}$ Felicia R. Lee, The Homeless Sue for Toilets in New York, N.Y. Times (Nov. 1, 1990), https://www.nytimes.com/1990/11/01/nyregion/the-homeless-sue-for-toilets-in-new-york.html [https://perma.cc/JJW2-XB7W].

${ }^{11}$ Mayor de Blasio Signs Legislation Increasing Access to Feminine Hygiene Products for Students, Shelter Residents and Inmates, OFF. WeBsite OF THE CITY OF N.Y. (2016), http://wwwl.nyc.gov/office-of-themayor/news/611-16/mayor-de-blasio-signs-legislation-increasing-access-feminine-hygiene-productsstudents- [https://perma.cc/NYU8-Y8CH].

${ }^{12}$ Nancy Fraser, Rethinking Recognition, 3 New Left Rev. 107, 114-15 (2000).

${ }^{13}$ Inga T. Winkler, Human Rights Shine a Light on Unmet Menstrual Health Needs and Menstruation at the Margins, 133 OBSTETRICS \& GyNECOLOGY 235, 235-37 (2019).
} 


\section{Pay Toilets and Potty Parity}

Although pay toilets are a common feature of public life in countries like the U.K. and France, they disappeared in the U.S. in the late seventies owing to mounting pressure from women's rights activists who argued that paid stalls penalized women for simply existing in spaces built without their needs in mind. ${ }^{14}$ Similarly, the push for "potty parity" emerged after women's advocates argued gendered differences in wait times for restrooms amounted to de facto discrimination. ${ }^{15}$ Prior to 1988 , when plumbing codes were amended to require an equal ratio of water closets in public spaces, plumbing guidelines allocated equal square footage for men and women, which failed to consider differences in urinary frequency, gendered parenting, and menstrual hygiene. ${ }^{16}$ Between 1987 and 2005, over twenty states enacted laws that required anywhere from a 2:1-4:1 ratio of toilets, favoring women, in specified public spaces. In 2005, NYC amended building codes and enacted a 2:1 ratio in arenas, bars, and theaters. ${ }^{17}$

\section{Gender Nondiscrimination}

Recent local and state laws have sought to address the discrimination faced by people who identify as transgender or as gender nonconforming. Barriers related to menstrual management represent a dimension of this discrimination. While menstrual products and disposal units are common (but not guaranteed) in women's restrooms, their absence in men's restrooms discriminates against trans men and nonbinary people who menstruate. ${ }^{18}$ Laws to address this enable individuals to choose restrooms that correspond with their own gender identification and mandate gender-neutral signs for single user restrooms. In addition to enabling safe and dignified experiences for gender minority groups, potty parity advocates recognize gender-neutral restrooms as a way to reduce gendered

\footnotetext{
${ }^{14}$ Kathryn H. Anthony, Defined by Design : The Surprising Power of Hidden Gender, Age, And Body Bias in EVeryday Products and Places 70 (2017).

${ }^{15}$ Clara Greed \& Peter Greenaway, The Role of the Public Toilet in Civic Life, in LADIES AND GENTS 35-47 (Olga Gershenson \& Barbara Penner eds., 2009).

${ }^{16}$ Kathryn H. Anthony \& Meghan Dufresne, Potty Parity in Perspective: Gender and Family Issues in Planning and Designing Public Restrooms, 21 J. Plan. Literature 267, 279 (2007).

${ }^{17}$ City of N.Y., Local Law 57 of 2005 (June 6, 2005).

${ }^{18}$ Gabriel Arkles \& Jennifer Weiss-Wolf, Menstruation-Related Discrimination is Sex Discrimination-We Don't Need to Erase Trans or Non-Binary People to Make That Point, ACLU (Dec. 27, 2019), https://www.aclu.org/news/lgbt-rights/menstruation-related-discrimination-is-sex-discrimination-we-dontneed-to-erase-trans-or-non-binary-people-to-make-that-point/ [https://perma.cc/L33G-HN42].
} 
inequalities in wait times. ${ }^{19}$ For gender nonconforming individuals experiencing homelessness, access to gender-neutral facilities for managing menstruation may be particularly challenging.

\section{Public Restrooms and Public Health}

Their present-day disreputability notwithstanding, public toilets were once championed as necessary amenities of urban civic life. But public toilets faded from importance in postwar health priorities, despite evidence showing that individuals without consistent and reliable access to restrooms face documented risks to their health. This includes the exigencies of disease management and adverse health outcomes associated with urinary retention. ${ }^{20}$ Poor menstrual hygiene poses additional risks that intensify under conditions of residential instability. In addition to endangering health, restroom exclusion increases the likelihood of menstrual blood leakage or odors, which compound feelings of shame and stigma associated with being homeless and hinder efforts to blend in and improve life prospects. ${ }^{21}$ Because public hygiene could be ignored only at collective risk, COVID forced U.S. cities and states to reckon with this longstanding grievance by providing temporary relief through portable toilets and handwashing stations. ${ }^{22}$ Months after the onset of the pandemic, during which non-profit organizations managed access points for people without housing, NYC installed a dozen temporary portable restrooms and handwashing stations. Although gendered sanitation needs were never flagged, portable restrooms also provided a place for menstruation management. The victory was short-lived: Unreliable staging and occasional vandalism ensured their demise. ${ }^{23}$

\footnotetext{
${ }^{19}$ Anthony and Dufresne, supra note 16, at 267-68.

${ }^{20}$ Ron Hochbaum, Bathrooms as a Homeless Rights Issue, 98 N.C. L. REv. 205, $236-37$ (2020).

${ }^{21}$ Marni Sommer et al., Menstruation and Homelessness: Challenges Faced Living in Shelters and on the Street in New York City, Health \& Place, Nov. 2020, at 5.

${ }^{22}$ Interim Guidance for Homeless Service Providers to Plan and Respond to Coronavirus Disease 2019 (COVID-19), Ctrs. For Disease CONTROL \& Prevention (Oct. 31, 2020), https://www.cdc.gov/coronavirus/2019-ncov/community/homeless-shelters/plan-prepare-respond.html [https://perma.cc/CJ6Y-JV7P].

${ }^{23}$ Reuven Blau, No Bathroom Relief in Sight for Thousands Living on the Streets, CiTy (Aug. 13, 2020), https://www.thecity.nyc/2020/8/13/21365521/nyc-homeless-bathroom-penn-station-subways-manhattan [https://perma.cc/NV6K-KW26].
} 


\section{Persisting Issue of Restroom Availability}

Legislation to enhance inclusiveness and equality are important steps forward, but fail to address the underlying deficiency of functional, well-maintained, and reliablyavailable free public restrooms. Instead, existing legislation speaks primarily to patrons of what might be called "semi-public" spaces and ignores the structural inadequacy of restrooms for those who menstruate.

\section{A. Semi-Public Spaces}

The term "public restroom" has yet to be defined in this paper, and that imprecision itself is telling: In common parlance, it encompasses a range of facilities generally accessible to the public. This includes restrooms in privately-owned spaces (i.e., commercial establishments) that are typically made available to patrons, and restrooms in public domains that are accessible to all. Legislation that addresses the inadequate provision of public restrooms often targets the former while calls to increase the latter face resistance from policymakers.

Potty parity and gender nondiscrimination laws address unequal access but do not address supply. Such laws also fail to ensure access for individuals who cannot afford to make a purchase in order to qualify for semi-public restrooms. Although some may access semi-public facilities without a purchase, this dispensation is often restricted to those who uphold customary norms pertaining to appearance, resulting in instances where individuals are denied after making a purchase or refused service altogether. Thus, such laws not only discriminate based on ability to pay, but also privilege the ability to "pass." They also fail to accommodate anyone who needs to use the restroom frequently, or whose need is urgent, such as those with children, individuals with medical conditions, and people who menstruate. Given the gendered dimension of menstruation, access that hinges on patronage unfairly taxes women for gender-dependent exigencies and effectively extends the legacy of pay toilets.

\section{B. Addressing the Needs of People Who Menstruate}

Legislative efforts to improve access to toilet facilities for gender minorities and women are an important symbolic step, but they are insufficient to equip facilities to meet the needs of those who menstruate. These laws-focused primarily on "relabeling"perpetuate the problems associated with the status quo by ignoring underlying issues of 
short supply and exclusive design. ${ }^{24}$ Without equipping relabeled restrooms with disposal units and menstrual products, parity and gender nondiscrimination laws may actually intensify demand and worsen wait times. ${ }^{25}$ Substantial corrective efforts are further encumbered by the exemption of many buildings from enhanced toilet ratios, which apply only to new construction or substantial renovations. Delay is an elongated form of denial, and the slow pace of reform burdens anyone facing menstrual health challenges.

A few recent public efforts, inspired by government strategies abroad, include singleuser toilets (stand-alone stalls in public spaces), and public-private partnerships to supply public toilets. The first have had mixed success. They were closed in Seattle and San Diego and have received public backlash in San Francisco due to unanticipated costs, odors, and complaints about criminal activity in and around the stalls. ${ }^{26}$ In 2008 , Portland installed the prototype of what has been widely regarded as a successful model for singleuser toilets, due to design features that mitigate misuse and ease maintenance. The "Portland Loo" has been implemented in cities throughout the country. ${ }^{27} \mathrm{NYC}$ attempted single-user toilets in 2008, announcing a program to install twenty single-user toilets that would be available for a small fee. Exempted from state law banning pay toilets, and secured by a twenty-year installation and operation deal, NYC was only able to install five toilets due to difficulties securing suitable locations. ${ }^{28}$

\footnotetext{
${ }^{24}$ Joellen Kralik, “Bathroom Bill” Legislative Tracking, NAT'L CONF. ON State LegiSLATURES (Oct. 14, 2019), https://www.ncsl.org/research/education/-bathroom-bill-legislative-tracking635951130.aspx [https://perma.cc/UD7H-VM2Y].

${ }^{25}$ Clara Greed, Join the Queue: Including Women's Toilet Needs in Public Space, 67 Soc. Rev. 908, 916-17 (2019).

${ }^{26}$ David Garrick, San Diego Yanks Problem Portland Loo, SAN DiEgo Union-Tribune (Feb. 5, 2016), https://www.sandiegouniontribune.com/news/politics/sdut-portland-loo-remove-crime-cost-restroom2016feb05-story.html [https://perma.cc/EL2B-S4YT] ; Sarah Anne Lloyd, Seattle to Give Outdoor Bathrooms Another Shot in Ballard, CuRBed SeATtLe (Nov. 16, 2018), https://seattle.curbed.com/2018/11/16/18099390/seattle-ballard-public-bathroom-installation; C. W. Nevius, It's Time to Raise a Stink Over Public Toilets, SFGATE (Dec. 10, 2011), https://www.sfgate.com/bayarea/nevius/article/It-s-time-to-raise-a-stink-over-public-toilets-2393868.php.

${ }^{27}$ Marcia Bernbaum, Findings and TaKe-AWays for Washington D.C. From a Questionnaire Administered to Cities that Have Installed the Portland Loo i (2019).

${ }^{28}$ Sarina Trangle, Finding a Public Toilet in NYC still Difficult 10 Years into Program Launch, AMN.Y. (Feb. 5, 2018), https://www.amny.com/news/new-york-public-toilets-1-16544793/ [https://perma.cc/CMX4Y4AT].
} 
The second strategy incentivizes select retail establishments or business districts to provide the general public access to existing patron restrooms. Although these partnerships are common throughout Europe, only Washington, D.C., and NYC have taken steps towards trying them. In NYC's pilot program, civil penalties for Title 20 violations are waived for participating businesses in exchange for providing public access to restrooms. ${ }^{29}$ Advocates hail the cost-savings associated with not having to install and maintain public restrooms, while increasing the number of public restrooms. Potentially, this could address the class discrimination cited earlier that occurs when access is restricted to paying customers; in principle, it could even increase the number of restrooms available to individuals experiencing homelessness.

\section{Challenges to Implementation}

Efforts to provide truly public restrooms at sufficient scale face significant barriers. Although public toilets could address issues specific to menstruation by providing a reliable and free place to manage periods, ongoing menstrual stigma prevents those who menstruate from being vocal advocates for public toilet provision and prevents menstruation from being the focus of larger conversations about public toilet provision.

Accommodating partnerships with private businesses tend to observe business hours, with implications for toilet availability. Community Schemes in London have been criticized for failing to provide twenty-four-hour access. ${ }^{30} \mathrm{NYC}$ 's pilot program is not enforced between 10 p.m. and 6 a.m., thus ignoring the needs of individuals experiencing homelessness or others out after hours. Additional challenges include policy enforcement. Commercial participation in the NYC program is voluntary and adherence depends upon informal public monitoring and notification. Success is thus dependent on knowledgeable, motivated individuals in a position to file complaints. This effectively excludes many of those for whom this program could be most impactful. Owing to the closure of private establishments during the onset of COVID, and subsequent guidelines limiting the number of patrons, the implementation of these partnerships has largely stalled.

\footnotetext{
${ }^{29}$ Gabriel Sandoval, For Fine Relief, Stores Could Open Their Restrooms to the Public, CiTy (Jan. 27, 2020), https://www.thecity.nyc/government/2020/1/27/21210552/for-fine-relief-stores-could-open-their-restroomsto-the-public [https://perma.cc/Z68V-Y7NJ].

${ }^{30}$ Clara Greed, Taking Women's Bodily Functions into Account in Urban Planning and Policy: Public Toilets and Menstruation, 87 Town Plan. Rev. 505, 513 (2020).
} 
Monitoring and site selection are especially relevant for single-user toilets. Experience demonstrates the importance of routinely monitored, carefully-designed and maintained toilets in strategically-selected locations. Although the Portland Loo is designed to minimize criminal activity, San Diego's attempt in 2015 was short-lived, and the city opted instead for $24 / 7$ access to monitored restrooms in select homeless shelters. Other cities have had more success, but the San Diego experience shows that design itself cannot substitute for monitoring and site selection. ${ }^{31}$

\section{CONCLUSION}

Proponents of well-maintained, respectably resourced public toilets face considerable difficulties. Their efforts are not eased by folding this provision into a rights-based argument for participatory parity in the public sphere and incur further labor when highlighting the menstrual or other sanitation-related needs of mobile New Yorkers, especially those precariously housed. Nonetheless, we believe that a pandemic-hardened public health authority would be wise to tackle that challenge, and to do so on several fronts that are mindful of safety, accessibility, cost, and the needs of menstruating people.

First, laws should equip all public restrooms with disposal and dispensing units for menstrual products. Second, the exploration of public and private partnerships similar to the penalty mitigation program should be resumed post-COVID. These partnerships can rapidly increase toilet availability through a low-cost approach that benefits from existing resources, or provide maintenance and monitoring, as demonstrated in the upkeep of Bryant Park's restrooms as part of a Business Improvement District. These partnerships could also reclaim NYC's neglected public toilet "fleet," including restrooms in subways and parks, by providing advertising space in exchange for maintenance and monitoring. In light of COVID health concerns, an appropriate short-term option would be to experimentally install a user-friendly single-toilet scheme showcased by the Portland Loo, and assess its viability after a six-month trial period. To address the needs of people experiencing homelessness, shelters could make toilets accessible all day. Finally, awareness campaigns are needed to direct public attention to existing resources and legal rights to access. This includes public toilets that are "hidden" within municipal buildings, those in retail establishments participating in incentive programs, and existing single-user toilets in NYC.

Meeting fundamental needs without shame while in public is critical to human dignity in urban settings. Basic sanitation and menstrual management should be leverage

\footnotetext{
${ }^{31}$ Garrick, supra note 26.
} 
enough, but these are parlous times for public health. The realities of COVID-19 add urgency to provision of a public good that should have been secured long ago. 